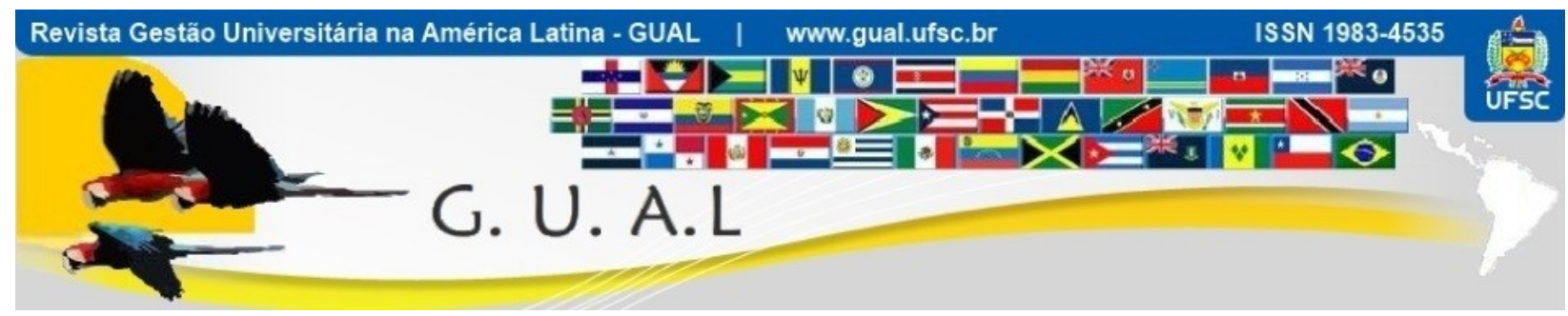

DOI: http://dx.doi.org/10.5007/1983-4535.2015v8n2p90

\title{
AS COMPETÊNCIAS VIRTUAIS INDIVIDUAIS DESENVOLVIDAS PELA GRADUAÇÃO A DISTÂNCIA EM UM CURSO DE ADMINISTRAÇÃO: O CASO DA UNIVERSIDADE FEDERAL DE SANTA CATARINA
}

\section{INDIVIDUAL VIRTUAL COMPETENCES DEVELOPED BY A DISTANCE EDUCATION BUSINESS ADMINISTRATION COURSE: THE CASE OF UNIVERSIDADE FEDERAL DE SANTA CATARINA}

Ariane Rodrigues Pereira, Mestre Faculdade de Engenharia da Universidade do Porto - FEUP - Portugal arianerp@gmail.com

Marcos Baptista Lopez Dalmau, Doutor Universidade Federal de Santa Catarina - UFSC marcos.dalmau@ufsc.br

Apoio: Durante a realização deste trabalho a autora contou com o apoio financeiro da Capes por meio de bolsa de estudos.

Recebido em 18/abril/2014

Aprovado em 15/abril/2015

Sistema de Avaliação: Double Blind Review

Esta obra está sob uma Licença Creative Commons Atribuição-Uso. 


\title{
RESUMO
}

O presente trabalho descreve a percepção de alunos de graduação quanto ao desenvolvimento de competências virtuais individuais - CVI no curso de administração modalidade Educação a Distância - EaD da Universidade Federal de Santa Catarina. Para tanto, a pesquisa foi conduzida dentro de uma abordagem fenomenológica e pode ser caracterizada como qualiquanti, aplicada e descritiva. Realizada num estudo transversal e compreendida como um estudo de caso. Utilizou se entrevistas semi-estruturadas e levantamento (surveys), o qual foi composto por questionário com perguntas fechadas e respostas em escala likert. Os dados foram tratados de forma a analisar a contribuição do curso de administração EaD para o desenvolvimento das CVIs. Foi utilizado o modelo de Wang e Haggert (2011) como base para a verificação dos componentes constituintes do construto CVI, a saber: autoeficácia virtual, habilidade com mídia virtual e habilidade social virtual. A partir deste modelo houve um levantamento das principais CVIs demandas para o profissional de administração. Os resultados preliminares apontam que o curso contribui para o desenvolvimento das CVIs. No entanto, o estímulo para que os alunos trabalhem em conjunto de forma virtual tem sido maior por parte dos colegas.

Palavras-chave: Competências Virtuais Individuais. Gestão EaD. Formação Profissional Administrador.

\begin{abstract}
This paper presents the perceptions of undergraduate students in regards to the individual virtual competence - CVI development. This study occurred in a business administration distance education course at Universidade Federal de Santa Catarina. Hence, the research was carried out according to the phenomenological approach and can be characterized as qualitative and quantitative, furthermore as applied and descriptive. It is a cross-sectional study, comprised by a case study. The data treatment was done by means of analyze CVI's development. In order to do so it was used the following research categories: virtual selfefficacy - VSE; virtual social ability - VSA; and, virtual media ability - VMA, that are developments that make up the construct Individual Virtual Competence - IVC as proposed by Wang and Haggerty (2011). Furthermore it was analyzed the virtual competences that are the most wanted by managers. The result shows that the course has done contributions to the IVC's development. However, the stimulus for students to work together in virtual form has been higher from colleagues than by an institutional guideline.
\end{abstract}

Key-words: Individual Virtual Competence. DE Management. Administrator Professional Formation 


\section{INTRODUÇÃO}

Em se tratando do ambiente de aprendizagem, de fato, a crescente influência das tecnologias de informação e comunicação tem propiciado uma mudança de paradigma para alunos, educadores e demais profissionais da educação. E isto representa desafios e inovações no campo educacional. Ilustrativamente, é possível citar o caso do Twitter de Biz Stone, e, em o Ipad e tablets. Sendo que este último tem uma grande potencialidade para a possibilidade de bibliotecas digitais e até mesmo uma reinvenção da pedagogia, Ristoff (2011).

A sociedade da informação e os avanços tecnológicos em TICs permitiram autonomia ao estudante para construir seu próprio conhecimento, a partir de informações e conhecimentos prévios e com o apoio e orientação de tutores e professores. Neste tocante, é importante compreender a realidade, as tecnologias e as ferramentas que contribuem para o processo de ensino-aprendizagem; a fim de oferecer métodos, ritmos e aulas compatíveis com os benefícios e facilidades que a convergência tecnológica e a virtualidade proporcionam.

Com o intuito de contribuir para o aprendizado virtual, tem-se a metodologia de desenvolvimento de competências, que valoriza contextos profissionais específicos. Este sistema focaliza no indivíduo, o qual pode buscar a realização de atividades de aprendizado e desenvolver habilidades e competências que o capacitem a realizar trabalhos colaborativos e cooperativos de forma virtual.

Nesse contexto, o sistema Universidade Aberta do Brasil através da Educação a Distância - EaD mostra-se como uma oportunidade de expansão ao acesso à graduação, como também oferece o paradigma da EaD como articuladora de uma estratégia tecnológica que contempla novas metodologias e técnicas didático-pedagógica num contexto virtual e facilitador.

A proposta do curso de administração EaD/UFSC ofertado pela UAB é a de desenvolver competências no aluno que o habilite às permanentes mudanças que o presente desenvolvimento tanto científico quanto tecnológico impõe - EAD/UFSC (2012). Assim, a verificação se ocorre, e em que nível ocorre, o desenvolvimento das competências virtuais individuais - CVIs torna-se necessária já que o curso utiliza-se de plataformas digitais, que possibilitam a integração e a interatividade de alunos-tutores-professores.

Para Chudoba, Wynn, Lu e Watson-Manheim (2005) a todo o tempo as pessoas se tornam mais virtuais. E, no contexto organizacional, isto também tem ocorrido, a maior parte do trabalho atualmente demonstra características de virtualidade, Wang e Haggerty (2011). 
Assim, o administrador é um profissional que necessita estar em consonância com as atualizações tecnológicas.

Dessa forma, tendo em vista as necessidades que o mercado tem imposto no tocante às CVIs e a realidade de preparação que o profissional de administração adquire num curso de graduação $\mathrm{EaD}$, a presente pesquisa analisou quais competências virtuais são desenvolvidas pelo curso de administração $\mathrm{EaD} / \mathrm{UFSC} / \mathrm{UAB}$ e em que nível elas foram desenvolvidas.

\section{O PROFISSIONAL DE ADMINISTRAÇÃO E AS COMPETÊNCIAS VIRTUAIS}

Diversas são as áreas de atuação que o administrador pode exercer seu ofício. De acordo com o Conselho Federal de Administração - CFA (2012) o campo de atuação é vasto e inclui as seguintes áreas: Administração e Seleção de Pessoal/Recursos Humanos; Organização e Métodos/Análise de Sistemas; Orçamento; Administração de Material/Logística; Administração Financeira; Administração Mercadológica /Marketing; Administração de Produção; Relações Industriais/ Benefícios/ Segurança do Trabalho. Há ainda alguns campos compreendidos como desdobramentos ou conexos que propiciam a possibilidade de atuação nas seguintes áreas - Administração de Consórcio; Administração de Comércio Exterior; Administração de Cooperativas; Administração Hospitalar; Administração de Condomínios; Administração de Imóveis; Administração de Processamento de Dados/ Informática; Administração Rural; Administração Hoteleira; Factoring e Turismo.

Notadamente, todas essas áreas de atuação apresentam em maior ou menor grau trabalhos com características de virtualidade, já que de acordo com Wang e Haggerty (2011) há um continuum de trabalho que pode ser entendido como todos os trabalhos possuem algum grau de virtualidade, ou seja, os trabalhos não podem simplesmente ser classificados como apenas virtual ou não.

O termo virtual é um tema presente em diversas áreas, tais como engenharias, sistemas de informação, filosofia, administração e educação, sua conceituação tem sido objeto de debate. Utiliza-se na presente pesquisa a definição de que o termo virtual corresponde a algo transversal a múltiplos contextos institucionais, Chudoba et al (2003).

Tendo em vista essa definição é válido compreender a importância que o contexto virtual tem exercido nas sociedades e mercados de trabalho. Pois, a virtualidade perpassa as diversas esferas intra-organizacionais e extra-organizacionais. E dessa forma, influencia as chamadas organizações virtuais que para Yonemoto (2004) são organizações com 
desprendimento do aqui e agora. Ou seja, há uma liberdade em relação aos limites geográficos e temporais. Há um fluxo de informações do interior para o exterior e do exterior para o interior, possibilitando ao trabalhador atuar, por exemplo, em um home-office.

Assim, as organizações com características virtuais acabam por determinar novas especificidades para o ambiente de trabalho: acessar a internet, reunir informações, ter proficiência no uso de planilhas e ferramentas eletrônicas, desempenhar trabalhos colaborativos de forma virtual, enfim, ter competências que o capacitem a desempenhar suas atividades num contexto permeado pela virtualidade. E neste, tocante com relação ao administrador algumas exigências se sobressaem, a saber: desenvoltura, qualidade e agilidade, principalmente no uso de todas as ferramentas disponíveis, inclusive as de informática, Heleno (2008).

Para Malhotra e Majchrzak (2014) cada vez mais equipes de trabalho dispersas geograficamente tem demandado exclusivamente o uso de TICs para coordenar conhecimento e realizar atividades colaborativas. Assim, para se manter empregável no mercado brasileiro, que está de acordo com Franco (2005, p. 66) em crescente processo de abertura internacional "é necessário possuir qualidades suficientes para disputar em posição de igualdade contra qualquer concorrente". E, é neste tocante que entra a questão do desenvolvimento de competências virtuais para o administrador.

\subsection{DESENVOLVIMENTO DE COMPETÊNCIAS, VIRTUALIDADE E FORMAÇÃO}

Em se tratando da definição do conceito de competência a tônica da vertente francesa Zarifian (2001) e Le Boterf (2003) é a de que este conceito está ligado à concepção de agregação de valor e entrega tendo em vista um contexto específico de forma independente do cargo.

Zarifian (2001) argumenta que competência é a atitude de tomar iniciativa e assumir responsabilidades diante de situações profissionais com as quais o individuo se depara. Para isso, é necessário conhecimento, que possibilita o individuo agir em uma dada situação e o exercício reflexivo a fim de que o sujeito utilize suas aprendizagens em favor das situações.

Conquanto para Le Boterf (2003) a competência envolve saber como mobilizar, integrar e transferir os conhecimentos, recursos e habilidades, num determinado contexto profissional. Assim, espera-se que o profissional não se atenha ao que lhe é prescrito, mas que vá além. Contudo, a competência para Le Boterf (2003, p. 52) não pode ser compreendida 
como uma lista de características, já que "ela se exerce em um contexto particular. É contingente. Sempre há 'competência de' ou 'competência para', o que significa dizer que toda competência é finalizada (ou funcional) e contextualizada".

$\mathrm{Na}$ metodologia de desenvolvimento de competência há espaço para inovações educacionais como autogestão do aprendizado; diálogo entre teoria e prática; validação de aprendizados anteriores e a adoção de novas teorias de aprendizado, como o aprendizado autêntico e construtivismo social, Mulder, Weigel e Collins (2007).

Adicionalmente, para Håland e Tjora (2006) tanto o conhecimento quanto a competência são importantes parâmetros que diferenciam as organizações em se tratando de concorrência no mercado. Além disso, são fundamentais para identificar, desenvolver e sustentar as competências essenciais das organizações, o que ocorre por meio das pessoas. Neste tocante, observa-se que a formação baseada em competência permite que haja uma ênfase no contexto de trabalho, para dessa forma combinar a teoria e a prática. E é neste contexto que emerge a necessidade do desenvolvimento da competência virtual individual para fazer face ao contexto do trabalho virtual que surge como tendência nas organizações.

Assim, a presente investigação abarca o conceito de Wang e Haggerty (2008) de que competência virtual é uma extensão dos conhecimentos habilidades e atitudes de um indivíduo para trabalhar e se comunicar em ambientes virtuais com o propósito de completar projetos virtuais colaborativos.

Esse construto Competência Virtual Individual - CVI é composto pela autoeficácia virtual, habilidade com mídia virtual e habilidade social virtual, Wang e Haggerty (2008); sendo assim, é possível pensar em nível esperado de desenvolvimento para esta competência - CVI, bem como, em metodologias para o aprimoramento dos componentes deste construto.

É válido salientar que o desenvolvimento de competência está pautado na filosofia de treinamento e desenvolvimento, pois, a competência é algo individual, Alles (2005). Corrobora a isto a visão de Bohlander, Snell e Sherman (2005), de que uma alternativa para se aprimorar os níveis dos CHAs (conhecimentos, habilidades e atitudes) é pensar em T\&D para que estes proporcionem um desempenho satisfatório dos indivíduos.

E, em se tratando de desenvolvimento, a parceria das TICs e do construtivismo foram sobremodo importante, pois influenciaram positivamente ao aporte e contribuição do trabalho e aprendizado colaborativo, ao desenvolvimento de competências, possibilidades de ferramentas para autoavaliação e aprendizado independente, Martens et al (2009). 
Para Campos (2009) a EaD é uma ferramenta que pode servir como mediadora da aprendizagem durante toda a vida, e neste tocante $(2009$, p. 272) "a alteração conceitual da visão educacional passou a situar a educação com uma relação direta com a capacitação tecnológica". E isto coincide com a necessidade do T\&D em competências virtuais individuais, já que o indivíduo pode usufruir tanto da interação tecnológica para seu desenvolvimento quanto para a sua empregabilidade.

Dessa forma, a EaD pode ser compreendida como uma modalidade adequada ao desenvolvimento individual por meio da oferta de cursos de graduação. Para o aluno esta opção representa uma maior facilidade de acesso, uma ampliação da possibilidade de relacionamentos em rede, e sobretudo qualificação e aquisição de habilidade e competências.

Conquanto a aprendizagem cooperativa realizada a distância, esta possibilita a superação de limites geográficos e também a criação e desenvolvimento de redes de relacionamentos que não possuem limitações locais. Logo, diante do exposto, é possível compreender que a EaD enquanto opção metodológica de oferta de aprendizagem favorece uma visão mais universal das necessidades para a empregabilidade, Campos (2009).

\section{PROCEDIMENTOS METODOLÓGICOS}

A filosofia da pesquisa encontra apoio na vertente fenomenológica. A abordagem adotada é quali-quanti, sendo que a abordagem qualitativa permeia todo o estudo de caso que aborda o projeto piloto II, enquanto que a abordagem quantitativa ocorre na etapa do levantamento (survey) com alunos e tutores.

Nesta investigação, as categorias de análise baseiam-se na definição do construto Competência Virtual Individual de Wang e Haggerty (2011) composto pelos seguintes construtos: autoeficácia virtual, habilidade com mídia virtual e habilidade social virtual, detalhados a seguir:

\begin{tabular}{|l|l|}
\hline Dimensão & Síntese dos resultados de pesquisa que suportam a conexão com CVI \\
\hline $\begin{array}{l}\text { Autoeficácia } \\
\text { virtual }\end{array}$ & $\begin{array}{l}\text { Estudos sobre trabalho remoto e trabalho virtual, uso de tecnologia no trabalho e } \\
\text { aprendizagem em ambientes virtuais confirmam a importância da auto confiança como uma } \\
\text { crença motivacional chave que permite desempenhos capazes, portanto justifica-se sua } \\
\text { inclusão no CVI. }\end{array}$ \\
\hline $\begin{array}{l}\text { Habilidade } \\
\text { social virtual }\end{array}$ & $\begin{array}{l}\text { Estudos sobre o papel da confiança, construção de relacionamento, socialização e network } \\
\text { social situados em contextos virtuais confirmam o papel significante que a capacidade de } \\
\text { habilidades sociais exercem para o indivíduo ao melhorar vários resultados de trabalhos } \\
\text { virtuais. Pesquisas também indicaram que a falta de habilidades sociais contribui para a } \\
\text { perda de confiança, relacionamentos fracos, e riscos emergentes na interação de equipes } \\
\text { virtuais. Tendo esses aspectos em vista, esta dimensão foi incluída na CVI. }\end{array}$ \\
\hline Habilidade com & Estudos sobre confiança e liderança, a naturalidade da mídia, efetividade da comunicação \\
\hline
\end{tabular}


mídias virtuais

mediada por computador e o trabalho em organizações virtuais indicam a importância da capacidade do desempenho individual com ferramentas de mídia a fim de comunicar e compartilhar informações. Além disso, pesquisas recentes indicam que a disfunção numa equipe pode surgir à medida que indivíduos usam inadequadamente ou não usam as ferramentas de TICs disponibilizadas. Esses conjuntos de pesquisas suportaram a inclusão da habilidade com mídias virtuais na CVI.

Quadro 01 Resultados de pesquisa das dimensões que compõem a CVI

Fonte: Wang e Haggerty (2011, p. 329)

A análise de dados deu-se através de abordagem dedutiva, e para tanto, foi feito uso dos pressupostos teóricos abordados na pesquisa, houve a redução dos dados coletados, transcrição das entrevistas, categorização das informações, bem como interpretação e análise. Portanto, as categorias de análise utilizadas foram:

\begin{tabular}{|l|}
\hline Foco de análise \\
\hline Perfil dos sujeitos: formandos e recém-formados \\
\hline Percepção da gestão do curso quanto às competências virtuais \\
\hline Competências virtuais demandadas pelo mercado de trabalho \\
\hline Experiência de Estudo Virtual dos formandos \\
\hline Curso de Administração EaD - infraestrutura e recursos, competências e influência \\
\hline Autoeficácia virtual (autoeficácia computacional + autoeficácia em trabalho remoto) \\
\hline Habilidade com Mídia Virtual \\
\hline Habilidade Social Virtual \\
\hline
\end{tabular}

Quadro 02 Categorias de análise qualitativa.

Fonte: Elaborado pelos autores (2013).

No tocante à análise dos dados quantitativos, convém evidenciar que esses dados antes de passarem por um processamento e análise estão em estado bruto. Por conseguinte, foram processados para se tornarem úteis e serem transformados em informação, Saunders, Lewis e Tornhill (2009).

Assim, foram processadas as informações coletadas acerca de questões socioeconômicas como: idade, sexo, ocupação profissional, polo ao qual o(a) estudante esteve vinculado. Na segunda parte do questionário, baseada na Escala Likert, foram apresentadas perguntas referentes à percepção dos respondentes quanto aos construtos autoeficácia computacional, autoeficácia em trabalho remoto, habilidade social virtual, habilidade com mídia virtual, experiência diária com estudos virtuais, informações pertinentes à graduação em EaD, e, por fim, desenvolvimento de habilidades.

Para analisar tais dados foi utilizada abordagem estatística pautada essencialmente em distribuição de frequências e distribuição de frequências conjuntas para o cruzamento dos dados, além disse, para tratamento complementar dos dados contou com o uso de gráficos e 
tabelas que possibilitou à análise explorar, apresentar, descrever e analisar as relações dos dados.

A pesquisa esteve delimitada entre o período do segundo semestre de 2012 e primeiro semestre de 2013, portanto houve um recorte que abordou os formandos de 2012.2, 2013.1 como também contou com a participação dos recém-formados 2013.1. Dessa forma, a população-alvo importou na quantia de 196 alunos, no entanto, houve a participação efetiva de 24. Optou-se pela participação apenas de alunos concluintes, pois o desenvolvimento de competência requer tempo.

Contou-se ainda com a participação de 12 tutores: presenciais e a distância, de um total de 16. A percepção destes foi considerada já que estes acompanham de perto o desempenho dos alunos. Não obstante, a percepção da gestão do curso foi considerada através da participação da professora responsável pela gestão do curso, bem como pela profissional responsável pelo design instrucional e pela subcoordenadora de tutoria.

\section{RESULTADOS DA PESQUISA}

De acordo com a Pesquisa Nacional (2011) realizada pelo Conselho Federal de Administração as características diferenciadoras dos profissionais de administração são: Atuar com visão sistêmica da organização; Formar, liderar e motivar equipes de trabalho; Articular as diversas áreas da organização; Otimizar a utilização de recursos; Negociar conflitos e interesses; Gerar processos eficazes e aprendizagem organizacional; Desenvolver a gestão de conhecimento e Promover a interação com o ambiente externo. Notadamente são qualidades importantes para que as organizações atinjam seus resultados organizacionais.

Adicionalmente, a pesquisa do CFA (2011) elencou as competências, as habilidades e as atitudes mais demandados pelo mercado de trabalho na visão dos administradores respondentes da pesquisa. Os destaques no quesito competências foram: identificar problemas, formular e implantar soluções; ser capaz de enfrentar desafios e solucionar conflitos; desenvolver raciocínio lógico, crítico e analítico sobre a realidade organizacional; assumir o processo decisório das ações de planejamento, organização, direção e controle; desenvolver e socializar o conhecimento alcançado no ambiente de trabalho; e, elaborar e interpretar cenários.

Já para o Conselho Nacional de Educação - Câmara de Educação Superior que por meio da Resolução No 4, de 13 de julho de 2005 instituiu as Diretrizes Curriculares Nacionais 
do Curso de Graduação em Administração bacharelado, considera no Art. $4^{\circ}$. que a formação do administrador deve contemplar ao menos as seguintes competências:

I - reconhecer e definir problemas, equacionar soluções, pensar estrategicamente, introduzir modificações no processo produtivo, atuar preventivamente, transferir e generalizar conhecimentos e exercer, em diferentes graus de complexidade, o processo da tomada de decisão;

II - desenvolver expressão e comunicação compatíveis com o exercício profissional, inclusive nos processos de negociação e nas comunicações interpessoais ou intergrupais;

III - refletir e atuar criticamente sobre a esfera da produção, compreendendo sua posição e função na estrutura produtiva sob seu controle e gerenciamento;

IV - desenvolver raciocínio lógico, crítico e analítico para operar com valores e formulações matemáticas presentes nas relações formais e causais entre fenômenos produtivos, administrativos e de controle, bem assim expressando-se de modo crítico e criativo diante dos diferentes contextos organizacionais e sociais;

$\mathrm{V}$ - ter iniciativa, criatividade, determinação, vontade política e administrativa, vontade de aprender, abertura às mudanças e consciência da qualidade e das implicações éticas do seu exercício profissional;

VI - desenvolver capacidade de transferir conhecimentos da vida e da experiência cotidianas para o ambiente de trabalho e do seu campo de atuação profissional, em diferentes modelos organizacionais, revelando-se profissional adaptável;

VII - desenvolver capacidade para elaborar, implementar e consolidar projetos em organizações; e

VIII - desenvolver capacidade para realizar consultoria em gestão e administração, pareceres e perícias administrativas, gerenciais, organizacionais, estratégicos e operacionais.

Em suma, a ideia central das competências estabelecidas nas Diretrizes Curriculares orientam os cursos de graduação a formar um cidadão crítico e profissional que seja competente para atuar em seu ramo de atuação de forma a oferecer benefícios para sociedade e resultados organizacionais através de uma atuação pautada em valores e na ética.

Por sua vez, o trabalho intitulado "Competências individuais: um estudo com mestrandos em administração de instituições mineiras de ensino superior" elaborado por Anderson de Souza SantAnna, Maria Celeste Reis Lobo Vasconcelos, Lúcio Flávio Renault de Moraes, Vera L. Cançado apresenta resultados de análise psicométrica de escala proposta à 
mensuração do construto competências individuais. Neste estudo, os resultados das estatísticas descritivas utilizadas indicaram elevada demanda pelo conjunto das competências investigadas, SantAnna et al (2007).

Pela relevância desse estudo é apresentado a seguir o quadro com as competências individuais requeridas para um profissional de administração.

\begin{tabular}{|c|c|c|}
\hline \multirow{15}{*}{$\begin{array}{l}\text { Competências } \\
\text { Individuais } \\
\text { Requeridas }\end{array}$} & \multirow{8}{*}{$\begin{array}{c}\text { Competências } \\
\text { associadas ao saber- } \\
\text { fazer }\end{array}$} & Capacidade de aprender rapidamente novos conceitos e tecnologias \\
\hline & & Capacidade de trabalhar em equipes \\
\hline & & Criatividade \\
\hline & & Visão de mundo ampla e global \\
\hline & & Capacidade de comprometimento com os objetivos da organização \\
\hline & & $\begin{array}{l}\text { Domínio de novos conhecimentos técnicos associados ao exercício } \\
\text { do cargo ou função ocupada }\end{array}$ \\
\hline & & Capacidade de inovação \\
\hline & & Capacidade empreendedora \\
\hline & \multirow{7}{*}{$\begin{array}{c}\text { Competências } \\
\text { associadas ao saber- } \\
\text { ser e agir }\end{array}$} & Capacidade de comunicação \\
\hline & & Capacidade de lidar com incertezas e ambiguidades \\
\hline & & Capacidade de relacionamento interpessoal \\
\hline & & Iniciativa de ação e decisão \\
\hline & & Capacidade de gerar resultados efetivos \\
\hline & & Autocontrole emocional \\
\hline & & Capacidade de lidar com situações novas e inusitadas \\
\hline
\end{tabular}

Quadro 03 Agrupamento de indicadores por fator.

Fonte: SantAnna et al $(2007$, p. 8$)$

O quadro 03 proporciona uma classificação esquemática acerca das competências individuais requeridas dos profissionais de administração, organizadas de acordo com competências de saber fazer e aquelas associadas ao saber-ser e agir. Ou seja, está de acordo com a visão de Zarifian (2001) que aborda a mobilização de recursos de forma holística.

Diante do exposto: resultados da pesquisa nacional acerca do perfil do administrador, diretrizes curriculares e a pesquisa sobre as competências individuais requeridas, é possível compreender que o administrador é um profissional que tem formação generalista, contudo isto não implica que ele saiba de tudo um pouco, mas sim que possua "uma especialidade sem desconhecer as implicações do que faz para toda a organização de forma interconectada" Andrade e Amboni (2004, p. 35).

Tendo em vista que o enfoque da presente pesquisa são as competências virtuais individuais para o administrador, após análise das informações ora apresentadas, foi elaborada a seguinte relação de competências virtuais a serem analisadas nos formandos do curso de Administração-EaD/UFSC: Habilidade para realizar trabalhos colaborativos de forma virtual; Habilidade para criar e manter rede de relacionamento de forma virtual; Habilidade de 
aprender a utilizar novas ferramentas de TICs; Habilidade para utilizar novos programas; Habilidade para aprender novos conceitos; Habilidade de trabalhar em equipe de forma virtual; Habilidade para se expressar e se comunicar de forma virtual; e, Habilidade para transferir conhecimento de forma virtual.

O curso analisado faz parte do programa Universidade Aberta do Brasil, e, no tocante a gestão ele é denominado internamente como projeto piloto II. Atende 10 polos no estado de Santa Catarina. Além disso, conta com o apoio do Departamento de Ciências da Administração através do coordenador do curso de graduação em administração, do subcoordenador do curso de graduação em administração; de um coordenador de tutoria que é um professor do quadro efetivo; conselho editorial formado por professores do Departamento de Ciências da Administração - CAD; supervisores de tutoria presencial e a distância, tutores por disciplina; e um secretário.

De acordo com dados de entrevista, foi possível verificar que o curso trabalha numa perspectiva teórico metodológica sócio-interacionista, pautada na visão de Vygotsky. Esse pensador concebe a aprendizagem como um fenômeno que se realiza na interação com o outro. Então, por meio dos ambientes virtuais de ensino e aprendizagem busca-se incentivar a reflexão crítica e a construção coletiva do conhecimento na medida em que a comunicação e a interação entre os participantes, tutores e professores acontece por intermédio de ferramentas síncronas e assíncronas.

A organização curricular está planejada em formato modular, Projeto pedagógico (2010), e obedece ao que está proposto nas Diretrizes Curriculares dos Cursos de Graduação em Administração (Resolução 4 de 13 de julho de 2005).

Conforme preconizado no projeto pedagógico (2010) os princípios dinamizadores do currículo do curso são provenientes não apenas das abordagens epistemológica e metodológica do curso, mas também pela necessidade dos alunos terem uma abordagem teórico/prática dos conteúdos trabalhados, Projeto Pedagógico UAB (2010). E estes princípios estão em consonância com os resultados das entrevistas realizadas que demonstram que a cultura de aprendizagem que permeia o curso é a de se levar em conta a prática do aluno aliada a experiência do professor para explorarem o conteúdo a fim de aperfeiçoar a prática profissional do aluno. Principalmente, ao se ter em vista que o perfil do aluno tem sido predominantemente de estudantes que já são profissionais atuantes no mercado de trabalho, e, portanto, eles precisam aperfeiçoar suas habilidades técnicas. 
O curso faz uso do ambiente virtual - Moodle, que é uma ferramenta importante, já que possibilita o uso de diversos outros recursos como o chat, o fórum, troca de arquivos e troca de mensagens, além de ser uma plataforma aberta que permite aperfeiçoamentos e inovações em seu ambiente. Neste tocante, atualmente há chats disponíveis para aluno-aluno, aluno-tutor, aluno-professor, tutor-professor, o que caracteriza a comunicação multidirecional. Não obstante, o curso também conta com encontros presenciais para a realização de atividades acadêmicas.

Ainda concernente aos recursos utilizados, conforme salientado pela coordenadora de produção de materiais $\mathrm{EaD}$, os materiais didáticos são disponibilizados através de livros impressos para cada disciplina, vídeos-aula, CD-ROM, ambiente virtual, videoconferência, teleconferência e tutoria. Sendo que todos os recursos que o aluno recebe estão no AVA, mesmo ele recebendo o livro impresso ele recebe o livro em portable document format pdf, disponível no AVA; bem como as vídeo-aulas e arquivos de áudio das aulas também estão disponíveis no ambiente; e, todas as videoconferências são digitalizadas e disponibilizadas para o aluno. Ou seja, busca-se facilitar ao máximo a disponibilização de conteúdo para o aluno poder acessar seus estudos a qualquer hora e em qualquer lugar.

A percepção dos alunos levantada por meio de pesquisa. Tendo como categoria mais representativa de respondentes os formandos 2013.1 com 58\% de participação, seguido pelos formandos 2012.2 e 2012.1 com iguais índices de participação de $21 \%$ cada. A participação conforme o gênero feminino e masculino ficou equilibrada com $46 \%$ de participação e $54 \%$ respectivamente. A faixa etária apresentou consonância com o perfil nacional do aluno de EaD que tem uma idade de ingresso média de 28 anos e de conclusão de 31 anos, INEP/MEC (2010). Sendo assim, o destaque na presente pesquisa corresponde à faixa de 26 a 33 anos, conforme demonstra a tabela a seguir:

Tabela 01 Faixa etária dos alunos participantes.

\begin{tabular}{lll} 
Faixa etária & Respondentes & Distribuição \% \\
\hline Entre 19 e 25 anos & 3 & $13 \%$ \\
Entre 26 e 33 anos & 9 & $38 \%$ \\
Entre 34 e 41 anos & 4 & $17 \%$ \\
Entre 42 e 49 anos & 5 & $21 \%$ \\
Mais de 50 anos & 3 & $13 \%$ \\
\hline Total & $\mathbf{2 4}$ & $\mathbf{1 0 0 \%}$ \\
\hline
\end{tabular}

Fonte: Dados primários - elaborado pelos autores (2013) 
Convém evidenciar que se questionou aos alunos qual sua principal ocupação profissional, e, neste tocante houve predomínio de duas categorias: $50 \%$ dos respondentes são servidores públicos, enquanto $46 \%$ são empregados de empresa privada e $4 \%$ profissional liberal. As demais categorias: empresário, empregado rural, proprietário rural, desempregado e outros não tiveram respostas. Desta forma, tem-se que todos os respondentes estão trabalhando atualmente, e esta condição é importante para analisar as abstrações que são apresentadas a seguir, já que a extensão da competência virtual individual apresenta resultados não apenas em relação aos estudos, mas também em resultados práticos na vida profissional.

É válido ainda salientar que, a fim de compreender a realidade de estudo demandada pelo curso foram feitas perguntas aos alunos denominadas: Experiência de Estudo Virtual Cotidiano. Que consistiram em verificar a frequência com que o aluno utilizava a internet para busca de informações, comunicação e socialização com a finalidade de estudar. A seguir tabela com os resultados.

Tabela 02 Experiência de estudo virtual cotidiano

\begin{tabular}{|c|c|c|c|c|c|c|c|c|c|c|}
\hline \multirow{2}{*}{$\begin{array}{l}\text { Experiência de estudo virtual cotidiano } \\
\text { Em média, com que frequëncia você usa TIC, como... } \\
\text { 26. (...) a Internet, para a busca de informações para fins de estudo? }\end{array}$} & \multicolumn{2}{|c|}{ Raramente } & \multicolumn{2}{|c|}{$\begin{array}{c}\times \mathrm{p} / \\
\text { semana }\end{array}$} & \multicolumn{2}{|c|}{$\begin{array}{c}3 \times \mathrm{p} / \\
\text { semana }\end{array}$} & \multicolumn{2}{|c|}{$\begin{array}{c}5 \times \mathrm{p} / \\
\text { semana }\end{array}$} & \multicolumn{2}{|c|}{$\begin{array}{c}\text { Várias } \mathrm{x} \text { ao } \\
\text { dia } \\
\end{array}$} \\
\hline & 1 & $4 \%$ & & $0 \%$ & 8 & $33 \%$ & 4 & $17 \%$ & 11 & $46 \%$ \\
\hline & & & & & 12 & & & & & \\
\hline ?* & 1 & 30 & & $17^{\circ}$ & 6 & $26 \%$ & 0 & $26 \%$ & 0 & $0 \%$ \\
\hline
\end{tabular}

Fonte: Dados primários - elaborado pelos autores (2013)

* A pergunta 28 teve 23 respondentes.

É possível observar que o uso da internet para busca de informações com a finalidade de estudar apresenta altos percentuais em acessos de várias vezes ao dia $46 \%$ e 03 vezes por semana $33 \%$, tendo ainda aqueles que acessam 05 vezes por semana $17 \%$ e $4 \%$ raramente.

O uso da internet para comunicação com fins de estudo apresenta resultados mais expressivos em acessos de 03 vezes por semana $50 \%$ dos respondentes. Já a socialização é a característica que possui distribuição mais equilibrada: raramente são $30 \%$ dos respondentes, 01 vez por semana $17 \%$, 03 vezes por semana $26 \%$ e por fim 05 vezes por semana $26 \%$, com nenhuma resposta para várias vezes ao dia.

O uso da internet para busca de informações, comunicação e socialização representam atividades do cotidiano e que conforme Wang e Haggerty (2011) proporcionam oportunidades relevantes para indivíduos desenvolverem capacidades em atividades baseadas em TICs. O conhecimento do cenário, ou seja, em que tipo de atividades a internet é usada é importante 
para que profissionais de $\mathrm{EaD}$ possam orientar suas ações em busca do incremento do uso dessa tecnologia.

A fim de detalhar essa experiência de estudo virtual cotidiano, foi ainda questionado aos alunos a quantidade de horas/dia que estes utilizam a internet tendo em vista as mesmas situações das questões 26, 27 e 28. Os resultados são os que seguem:

Tabela 03 Experiência de estudo virtual cotidiano - por dia

\begin{tabular}{|c|c|c|c|c|c|c|c|c|c|c|}
\hline $\begin{array}{l}\text { Experiência de estudo virtual cotidiano } \\
\text { Em média, quanto tempo você gasta em TIC por dia, } \\
\text { como a internet, para... }\end{array}$ & \multicolumn{2}{|c|}{ Até 1 hora } & \multicolumn{2}{|c|}{ De 1 a 2 horas } & \multicolumn{2}{|c|}{ De 2 a 3 horas } & \multicolumn{2}{|c|}{ De 3 a 4 horas } & \multicolumn{2}{|c|}{$\begin{array}{c}\text { Mais do que } 4 \\
\text { horas }\end{array}$} \\
\hline 29. (...) a busca de informações para fins de estudo? & 7 & $29 \%$ & 8 & $33 \%$ & 6 & $25 \%$ & 1 & $4 \%$ & 2 & $8 \%$ \\
\hline 30. (...) para comunicação para fins de estudo? & 13 & $54 \%$ & 9 & $38 \%$ & 2 & $8 \%$ & 0 & $0 \%$ & 0 & $0 \%$ \\
\hline 31. (...) para socialização para fins de estudo? & 17 & $71 \%$ & 6 & $25 \%$ & 1 & $4 \%$ & 0 & $0 \%$ & 0 & $0 \%$ \\
\hline
\end{tabular}

Fonte: Elaborado pelos autores (2013)

Para as questões 29, 30 e 31 o percentual de $50 \%$ ou mais de respostas está concentrado em menores períodos de tempo, a saber: até 01 hora, e, de 1 a 2 horas. Através do conhecimento desse perfil dos alunos com relação ao tempo e finalidade de acesso à internet é possível planejar atividades de desenvolvimento que levem em conta essas características.

De forma geral é possível perceber que a internet é uma ferramenta muito utilizada pelos alunos para diversas finalidades. Sendo que a busca de informações predomina ao se considerar o total gasto nas faixas de horas. Mas, em se tratando de períodos de até 1 hora a finalidade de comunicação é a predominante. Essas três categorias: comunicação, busca de informações e socialização são utilizadas no modelo estrutural de competência virtual de Wang e Haggerty (2011), e foram validadas em estudos prévios como pesos que contribuem para a aferição da verificação da experiência cotidiana virtual.

Não obstante, em relação ao tema experiência de estudo virtual cotidiano, a fim de obter maior subsídio quanto ao uso de ferramentas colaborativas online e para comparar a frequência informada pelos alunos quanto à dedicação de tempo para estudos e demais atividades foram feitas as perguntas 33 e 34 :

Tabela 04 Experiência de estudo virtual cotidiano - atividades virtuais e colaborativas

\begin{tabular}{|c|c|c|c|c|c|c|c|c|}
\hline \multirow{2}{*}{$\begin{array}{l}\text { Experiência de estudo virtual cotidiano } \\
\text { Qual a frequëncia que você... } \\
\text { 33. (...) está envolvido em estudos/atividades virtuais nos últimos } 04 \\
\text { anos? }\end{array}$} & \multicolumn{2}{|c|}{$1 \times \mathrm{p} /$ semana } & \multicolumn{2}{|c|}{$3 x \mathrm{p} /$ semana } & \multicolumn{2}{|c|}{$5 x \mathrm{p} /$ semana } & \multicolumn{2}{|c|}{$\begin{array}{c}\text { Várias } x \\
\text { ao dia }\end{array}$} \\
\hline & 2 & $8 \%$ & 9 & $38 \%$ & 8 & 0 & 5 & $21 \%$ \\
\hline $\begin{array}{l}\text { 4. (...) você utiliza(ou) ferramenta colaborativa online como o msn, } \\
\text { talk, googledocs e/ou skype para realizar atividades acadêmicas? }\end{array}$ & 5 & $21 \%$ & 10 & $42 \%$ & 6 & $25 \%$ & 3 & $13 \%$ \\
\hline
\end{tabular}

Fonte: Dados primários - elaborado pelos autores (2013) 
A pergunta que faz referência aos estudos e atividades virtuais nos últimos 04 anos possui uma distribuição equilibrada das respostas, sendo que $8 \%$ dos alunos informaram que o fazem 01 vez por semana; $38 \%$ informaram realizar estudos/atividades 03 vezes por semana este foi o mais alto índice; $33 \%$ realizam 05 vezes por semana; e, apenas $21 \%$ realizam várias vezes ao dia. Essa realidade é diversa tendo em vista que o perfil profissional/educacional e as atividades demandadas para cada aluno pode variar. No entanto, é possível compreender que todos eles informaram estar envolvidos em atividades de contexto virtual.

Conquanto ao uso de ferramentas colaborativas online, como o MSN, gtalk, googledocs e skype a distribuição de respostas também esteve equilibrada, com $21 \%$ dos alunos informando que realizam o uso destas ferramentas $01 \mathrm{vez}$ por semana; a mais alta participação está em 03 vezes por semana com 42\% de participação; 05 vezes por semana aparece com $25 \%$ e o menor percentual está no uso várias vezes ao dia $13 \%$.

Um destaque importante que deve ser feito é que os alunos recebem mais incentivos e estímulos por parte de seus colegas para a adoção de ferramentas de TICs que os auxiliem a realizar trabalhos colaborativos. Foi perguntado aos alunos: No caso de ter recebido estimulo a trabalhar em conjunto de forma virtual, quem foi seu principal incentivador? As respostas assim se dividiram: professor $4 \%$, tutor presencial $25 \%$, tutor a distância $33 \%$ e colegas $38 \%$. Percebe-se que a maior parte dos estímulos parte dos próprios colegas. Em seguida está a contribuição dos tutores a distância e tutor presencial e em última opção dos professores. Dessa maneira, identifica-se que a contribuição mais lembrada pelos alunos parte de uma iniciativa não institucional, seguida pela contribuição dos tutores a distância.

Já tendo em vistas as competências virtuais desenvolvidas pelo curso, foram analisadas as competências listadas na tabela a seguir e para tanto, solicitou-se aos alunos que graduassem se houve ou não, e em caso de ter havido - qual nível de desenvolvimento obtido na competência. Os resultados obtidos apontam: 
Tabela 05 Competências Virtuais adquiridas no curso de graduação Administração-EaD

\begin{tabular}{|l|c|c|c|c|}
\hline \multicolumn{1}{|c|}{ Habilidades } & Muito & Médio & Pouco & Nada \\
\hline Realizar trabalhos colaborativos de forma virtual & $48 \%$ & $52 \%$ & $0 \%$ & $0 \%$ \\
\hline Usar ferramentas de TICs & $57 \%$ & $43 \%$ & $0 \%$ & $0 \%$ \\
\hline Criar e manter rede de relacionamento de forma virtual & $39 \%$ & $43 \%$ & $13 \%$ & $4 \%$ \\
\hline Aprender a utilizar novas ferramentas de TICs & $35 \%$ & $65 \%$ & $0 \%$ & $0 \%$ \\
\hline Utilizar novos programas & $39 \%$ & $48 \%$ & $9 \%$ & $4 \%$ \\
\hline Aprender novos conceitos & $48 \%$ & $48 \%$ & $4 \%$ & $0 \%$ \\
\hline Trabalhar em equipe de forma virtual & $35 \%$ & $52 \%$ & $13 \%$ & $0 \%$ \\
\hline Expressar e se comunicar de forma virtual & $43 \%$ & $48 \%$ & $9 \%$ & $0 \%$ \\
\hline Transferir conhecimento de forma virtual & $35 \%$ & $61 \%$ & $4 \%$ & $0 \%$ \\
\hline
\end{tabular}

Fonte: Dados primários - elaborado pelos autores (2013)

* O número de respondentes desta questão foi de 23 alunos.

Ao analisar a tabela acima é possível constatar que todas as habilidades foram desenvolvidas pelos alunos. Sendo que a que possui destaque é a habilidade de usar ferramentas de TICs representada por um percentual de 57\% na categoria muito. Ou seja, para os alunos foi significativa a evolução nesta habilidade ao fazer a graduação na modalidade a distância.

Em segundo lugar, tendo em vista as competências que foram sinalizadas com um alto desenvolvimento (muito), estão as habilidades de: realizar trabalhos colaborativos de forma virtual $48 \%$ e aprender novos conceitos 48\%. Estas estão em consonância com as competências associadas ao saber-fazer, tendo em vista as Competências Individuais Requeridas propostas por SantAnna et al (2007).

As competências relacionadas à habilidade de: expressar e se comunicar de forma virtual; criar e manter rede de relacionamento de forma virtual; apresentaram notas médias com relação ao desenvolvimento: $43 \%$ e $48 \%$ carecendo assim de maior atenção a fim de obter um melhor desempenho nestas características. Especialmente, porque houve alunos que marcaram que não houve desenvolvimento, $4 \%$ para cada categoria.

No modelo de Wang e Haggerty (2008) essas habilidades podem ser compreendidas como a Habilidade Social Virtual, já que representam um conjunto de habilidades do indivíduo para construir relacionamentos sociais com outras pessoas no ambiente virtual. Ainda no tocante às HSV as competências de trabalhar em equipe de forma virtual e transferir o conhecimento de forma virtual $52 \%$ e $61 \%$ obtiveram maior score dado pelos alunos.

Por fim, as habilidades: aprender a utilizar novas ferramentas de TICs e utilizar novos programas; apresentaram o desenvolvimento como médio: $65 \%$ e um pouco abaixo da média 
$42 \%$. Estas habilidades são chave para a competência virtual, uma vez que são compreendidas habilidades com mídia virtual, Wang e Haggerty (2011). Representa o nível de habilidade individual no uso de tecnologias para se comunicar com todo o seu potencial em configurações virtuais.

Além de verificar qual o nível de desenvolvimento obtido pelos alunos, foi questionado se a graduação em administração $\mathrm{EaD}$ contribuiu para o desenvolvimento dessas habilidades, e os resultados são os seguintes:

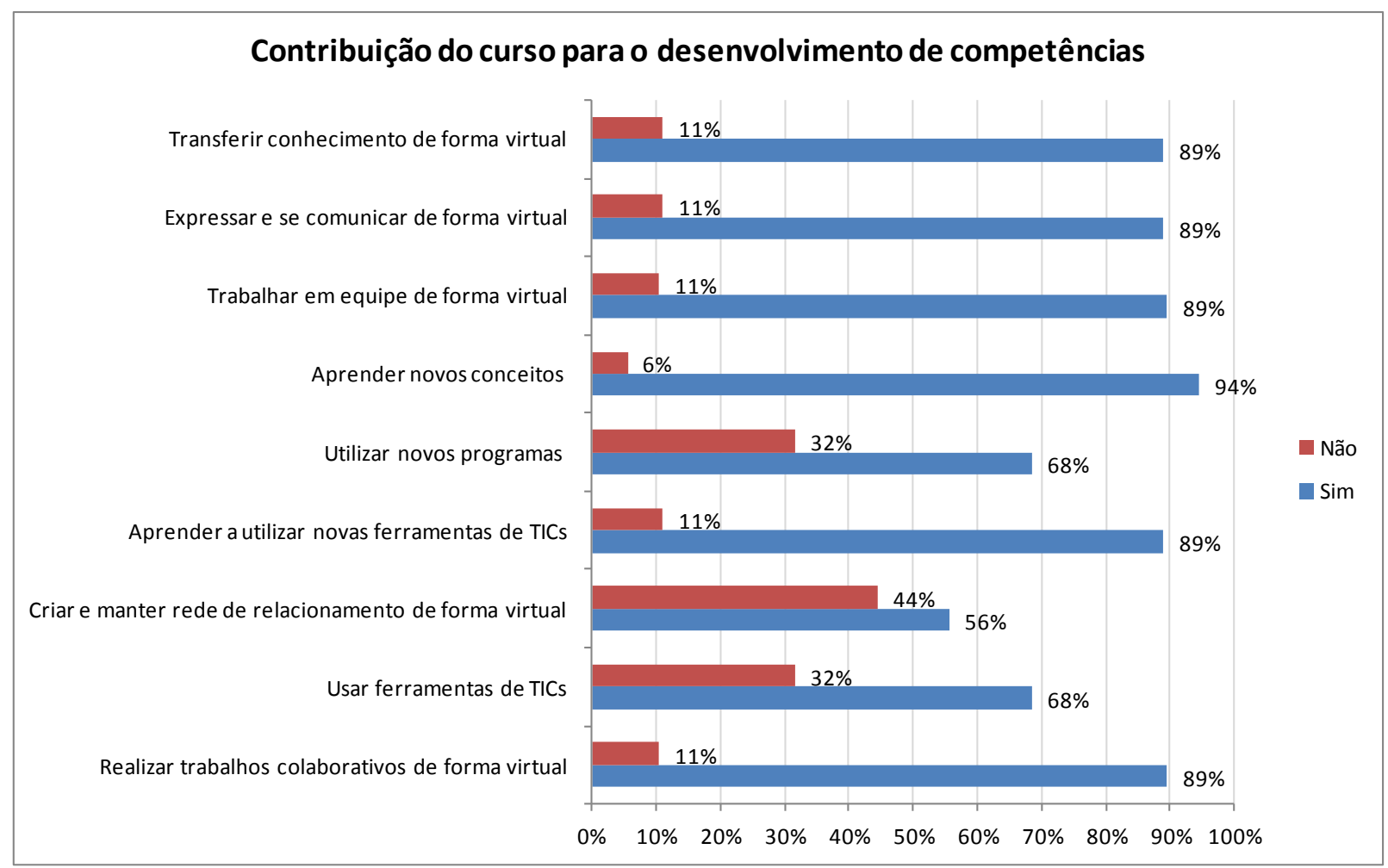

Gráfico 01 Análise da contribuição do curso para o desenvolvimento de competências virtuais Fonte: Dados primários - elaborado pelos autores (2013)

De todas as competências analisadas os alunos apontaram que o curso contribuiu para o desenvolvimento em todas elas, os percentuais de contribuição estão muito próximos com uma variação de $38 \%$ entre as habilidades que tiveram menor e maior contribuição: criar e manter rede de relacionamento de forma virtual $56 \%$, e, aprender novos conceitos que teve a maior participação com 94\%. Podendo esta última ser compreendida como a eficácia da Educação a Distância. Já no tocante à habilidade de criar e manter rede de relacionamento virtual, salienta-se que esta é uma habilidade associada a Habilidade Social Virtual que é uma das abstrações componentes da CVI. A importância da HSV reside no fato de que ela proporciona bases para o fortalecimento do relacionamento interpessoal. 
As habilidades que apresentam uma menor contribuição do curso são: utilizar novos programas 68\%; criar e manter relacionamento de forma virtual $56 \%$, e, usar ferramentas de tecnologia de comunicação e comunicação $68 \%$. Ou seja, por mais que o curso influenciou no desenvolvimento destas competências houve outras que mais se destacaram. E, desta forma, indica que há uma lacuna de desenvolvimento nestas habilidades.

As demais habilidades: Realizar trabalhos colaborativos de forma virtual; Aprender a utilizar novas ferramentas de TICs; Trabalhar em equipe de forma virtual; Expressar e comunicar de forma virtual; e, Transferir conhecimento de forma virtual - apresentaram coincidentemente um percentual de $89 \%$. O que indica na opinião dos alunos que o curso tem contribuído para o desenvolvimento da CVI.

Sendo que essas competências representam a autoeficacia virtual, que é um construto proposto por Wang e Haggerty (2011) composto pela autoeficacia em trabalho remoto e autoeficacia computacional. Representa a confiança da pessoa em desempenhar seu trabalho sem as interações face a face.

Um fato contrastante é que apesar de as últimas três habilidades terem tido um percentual de contribuição de $89 \%$ por parte do curso, para os alunos ainda não há um desenvolvimento de alto nível nestas habilidades, já que eles informaram que consideram que possuem um desenvolvimento médio nestas habilidades.

Dessa forma, é possível compreender que a graduação em administração modalidade $\mathrm{EaD}$ tem contribuído para a formação de profissionais que além de dominar as competências técnicas integradoras inerentes à sua função ainda possuem a vantagem de possuir a competência virtual individual.

É válido salientar que o aluno do curso de administração/EaD em sua grande maioria não possuía experiência prévia em cursos a distância, conforme é demonstrado pelos resultados da pergunta 32, que questionou: "32. Como você descreve sua experiência prévia com estudos virtuais antes de ingressar no curso de Administração - EaD?”. Os resultados foram: $58 \%$ não tinham experiência anterior, $33 \%$ possuíam experiência básica, e apenas $2 \%$ informaram possuir experiência intermediária. Para a opção experiência avançada não houve aluno que se manifestasse.

Os resultados apontados apresentam um quadro positivo quanto ao desenvolvimento das CVIs, em geral os alunos demonstraram que o curso os influenciou no desenvolvimento das habilidades elencadas. Entretanto, os índices apresentados não são homogêneos havendo, 
então, indício para que os alunos tivessem uma trilha de desenvolvimento personalizada a fim de potencializar o desempenho da CVI.

\section{CONSIDERAÇÕES FINAIS}

O administrador possui uma vantagem por ter uma habilitação que o capacita a atuar em diversas áreas. Se por um lado isto é vantajoso, por outro demanda que o administrador tenha diversas competências. E seja qual for a área que o profissional de administração irá atuar ele precisará estar capacitado nas competências virtuais individuais. Pois, o mercado já começa a exigir estas qualificações e exigirá tanto mais houver avanço em tecnologias de comunicação e de informação. Afinal há um continuum de trabalho, no qual há uma variação de virtualidade, não podendo mais hoje em dia o trabalho ser classificado apenas como virtual ou não, Wang e Haggerty (2011).

Porquanto as competências virtuais demandadas pelo mercado de trabalho e analisadas nesta pesquisa, foram: Habilidade para realizar trabalhos colaborativos de forma virtual; Habilidade para criar e manter rede de relacionamento de forma virtual; Habilidade de aprender a utilizar novas ferramentas de TICs; Habilidade para utilizar novos programas; Habilidade para aprender novos conceitos; Habilidade de trabalhar em equipe de forma virtual; Habilidade para se expressar e se comunicar de forma virtual; e, Habilidade para transferir conhecimento de forma virtual. Os alunos informaram que para todas elas houve desenvolvimento com predomínio das gradações médio e muito.

O desenvolvimento das competências virtuais é importante para o administrador, pois o conceito de competência proposto por Zarifian (2001) aborda a mobilização de recursos de forma holística. Sendo assim, o administrador pode valer-se das competências virtuais a fim de mobilizar e utilizar competências técnicas e comportamentais agregando valor a suas ações. E isto é importante para as organizações já que a virtualidade e o avanço das TICs têm se tornado cada vez mais evidente, e, tem transformado as relações intra e extraorganizacionais, Yonemoto (2004).

Logo, convém evidenciar a contribuição que o curso de graduação em administração na modalidade $\mathrm{EaD}$ oferecido pela UFSC fornece ao desenvolvimento da Competência Virtual Individual-CVI. Ressalta-se que a análise pautou-se nas características do curso Projeto Piloto II. Como subsídio das análises está a concepção de que o método de T\&D por competência tem como objetivo alinhar a lacuna entre o nível de competência desejado e o 
nível real de competência, Tecchio, Dalmau, Nunes e Tosta (2011). E, neste tocante, o curso de administração não possui formalmente qual o nível e competência virtual individual esperado dos formandos em administração.

Ao se considerar a avaliação das necessidades como um passo inicial para o planejamento das estratégias de desenvolvimento é válido informar que o curso não possui um diagnóstico quanto às competências virtuais no momento da admissão do aluno, e, sendo assim, também não possui uma ferramenta que avalie o desenvolvimento da CVI. As competências previstas no projeto pedagógico do Projeto Piloto II levaram em conta as diretrizes estabelecidas pelo Ministério da Educação - MEC.

Contudo, através da análise dos resultados da pesquisa é possível compreender que o curso influencia o desenvolvimento das competências virtuais individuais. O curso utiliza o Moodle como ambiente virtual de aprendizagem, o qual possui diversos recursos como o chat, fórum, troca de arquivos e mensagem, além de disponibilizar os materiais impressos de forma digital.

O estímulo para que os alunos trabalhem em conjunto de forma virtual tem sido maior por parte dos colegas, ou seja, essa orientação não tem sido pelo curso. Nota-se pela pesquisa realizada com os tutores que a maioria está habilitada no uso das ferramentas de comunicação e informação, no entanto, a orientação para fomentar o uso destas ferramentas que eles passam aos alunos não é uniforme, já que alguns alegam não receber esta orientação.

Portanto, compreende-se que os recursos adotados pelo curso estimulam o desenvolvimento da CVI nos alunos do curso de administração modalidade EaD/UFSC, já que ele possui recursos didáticos que valem-se do uso de plataformas e ferramentas digitais, não obstante, o projeto pedagógico e os planos de ensino das disciplinas oferecem espaço para o uso de recursos interativos para o desenvolvimento de competências. Contudo, há estratégias que podem ser adotadas institucionalmente para que aprimorem o desenvolvimento desta competência.

A adoção de um maior número de trabalhos colaborativos e cooperativos que demandem a integração virtual e associação de conhecimentos diversificados pode ser uma estratégia a ser explorada. A orientação para que tutores e professores estimulem o uso das TICs na execução das atividades acadêmicas também é alternativa viável para o desenvolvimento da CVI. Por fim, um instrumento para medição da CVI no momento de admissão e outro para a conseguinte avaliação na formação do aluno foram sugeridos à gestão 
do curso, a fim de proporcionar subsídios para a adoção e planejamento de ações no tocante às CVIs.

\section{REFERÊNCIAS}

ALLES, M. A. Desempeño por competencias: Evaluación de $360^{\circ}$. Buenos Aires: Granica, 2005.

ALMEIDA, E. B. de. Distance learning on the internet: approaches and contributions from digital learning environments. Educação e Pesquisa. São Paulo, v. 29, n.2, p. 327-340, jul/dez 2003.

ANDRADE, R. O. B. de; AMBONI, N. Gestão de cursos de administração: metodologias e diretrizes curriculares. São Paulo: Prentice Hall, 2004.

BOHLANDER, G; SNELL, S; SHERMAN, A. Treinamento e Desenvolvimento. In: Administração de Recursos humanos. São Paulo: Thomson, 2005.

BRASIL. Lei $\mathbf{N}^{\mathbf{0}} 4.769$ de 9 de setembro de 1965. Disponível em: http://www.planalto.gov.br/ccivil_03/leis/L4769.htm. Acesso em 12 de novembro de 2012.

CAMPOS, G. H. B. EAD: mediação e aprendizagem durante a vida toda. In: LITTO, Frederic Michael; FORMIGA, Manuel Marcos. Educação a distância: o estado da arte. São Paulo: Pearson Education do Brasil, 2009.

CONSELHO FEDERAL DE ADMINISTRAÇÃO - CFA. Campos de atuação. Disponível em: http://www2.cfa.org.br/fiscalizacao-registro/destaques/conteudo-1/teste-pagina-conteudo02 Acesso em 19 set 2012.

CHUDOBA, K. M; LU, M.; WYNN, E.; WATSON-MAHEIM, M. B. How virtual are we? Measuring virtuality and understanding its impact in a global organization. Information Systems Journal, 15, 4, october, 279-306, 2005.

FRANCO, S. Criando o próprio futuro. $6^{\text {a }}$ Ed. São Paulo: Futura, 2002.

GIL, A. C. Como elaborar projetos de pesquisa. São Paulo: Atlas, 2007.

HÅLAND, E; TJORA, A. Between asset and process: Developing competence by implementing a learning management system. Journal Human Relations, Volume 59(7): 993-1016, London, 2006.

HELENO, G. O administrador do futuro se faz presente. Revista Brasileira de Administração. Ano XVIII, nº 66, setembro/outubro, 2008.

INEP. Instituto Nacional de Estudos e Pesquisas Educacionais Anísio Teixeira. Censo da Educação Superior. Disponível em: http://portal.inep.gov.br/web/censo-da-educacaosuperior. Acesso em 16 de abril de 2013. 
MALHOTRA, A; MAJCHRZAK, A. Enhancing performance of geographically distributed teams through targeted use of information and communication technologies. Journal Human Relations, Vol. 67(4), p. 389-411, 2014.

MARTENS, R.; BASTIAENSB, T.; KIRSCHNER, P. A. New Learning Design in Distance Education: The impact on student perception and motivation. Distance Education, Vol. 28, No. 1, May 2007, pp. 81-93, 2007.

MULDER, M.; WEIGEL, T.; COLLINS, K. The concept of competence in the development of vocational education and training in selected EU member states: a critical analysis.

Journal of Vocational Education and Training, 59 (1), pp. 67-88, 2007.

RISTOFF, D. O futuro com inteligência. In: RISTOFF, D. Construindo outra educação: tendências e desafios da educação brasileira. Florianópolis: Insular, 2011.

SAUNDERS, M.; LEWIS, P.; THORNHILL, A. Research methods for business students, 5a ed. Harlow/England: Pearson Education Limited, 2009.

SANT'ANNA, A. de S.; VASCONCELOS, M ${ }^{\text {a }}$ C. R. L. de; MORAES, Lucio Flavio Renault de; CANÇADO, Vera. Competências Individuais: um estudo com mestrandos em administração de instituições mineiras de ensino superior. I Encontro de Gestão de Pessoas e Relações do Trabalho/ANPAD, Natal, 2007. Disponível em:

http://www.anpad.org.br/diversos/trabalhos/EnGPR/engpr_2007/ENGPR227.pdf

YONEMOTO, H. W. Proposta de integração entre ensino, aprendizagem, comunicação e virtualidade: uma arquitetura de reestruturação para o ensino superior. Florianópolis, 2004. 347 f. Tese (Doutorado) - Universidade Federal de Santa Catarina, Centro Tecnológico. Programa de Pós-Graduação em Engenharia de Produção.

WANG, Y.; HAGGERTY, N. Individual Virtual Competence and its influence on work outcomes. Journal of Management Information System, spring 2011, vol. 27, nr. 4, PP. 299-333, 2011.

. Knowledge transfer in virtual settings: The role of individual virtual competency. Information Systems Journal, 19, 6 (November) p. 571-593, 2008 .

ZARIFIAN, P. Objetivo competência: por uma nova lógica. São Paulo: Atlas, 2001. 